\title{
Unemployed physicians a sign of poor workforce planning
}

\author{
n Cite as: CMAJ 2019 June 10;191:E647-8. doi: 10.1503/cmaj.109-5760
}

Posted on cmajnews.com on May 22, 2019.

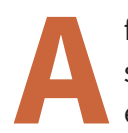

fter years of gruelling training, specialists might be forgiven for expecting it to be easy to find a job and put their hard-earned, indemand skills to work. But that is not always the case. Around $20 \%$ of specialists cannot find work at the time of their certification, according to a survey by the Royal College of Physicians and Surgeons of Canada.

This indicates fundamental problems with workforce planning in health care, said Danielle Fréchette, executive director of the Royal College's office of research, health policy and advocacy. Of course, people new to other professions with intensive education and training, such as law, also struggle to find work initially, but it is a more serious problem for physicians because they have fewer alternatives after they are certified, said Fréchette.

If jobs aren't available in their chosen specialties, they can't switch to other disciplines or go into family medicine without extensive retraining. Plus, by paying their salaries while they were residents, the government has a vested interest in ensuring newly qualified specialists can use their training.

"The state has invested in producing this health professional, so obviously it was felt that their skills were needed," said Fréchette.

The mismatch between the number of graduates and available jobs is due in part to a lack of data on future population health needs, so planners don't always know where the areas of greatest demand will be. Another problem is a lack of resources to support some specialties. The specialties for which the problem is most acute, with more than a quarter failing to find positions, include neurosur-
Dr. John Antoniou, president of the Canadian Orthopaedics Association, said the lack of jobs for orthopedic surgeons is not for lack of demand. Canada has the lowest number of orthopedic surgeons per capita and the longest wait times for elective procedures in

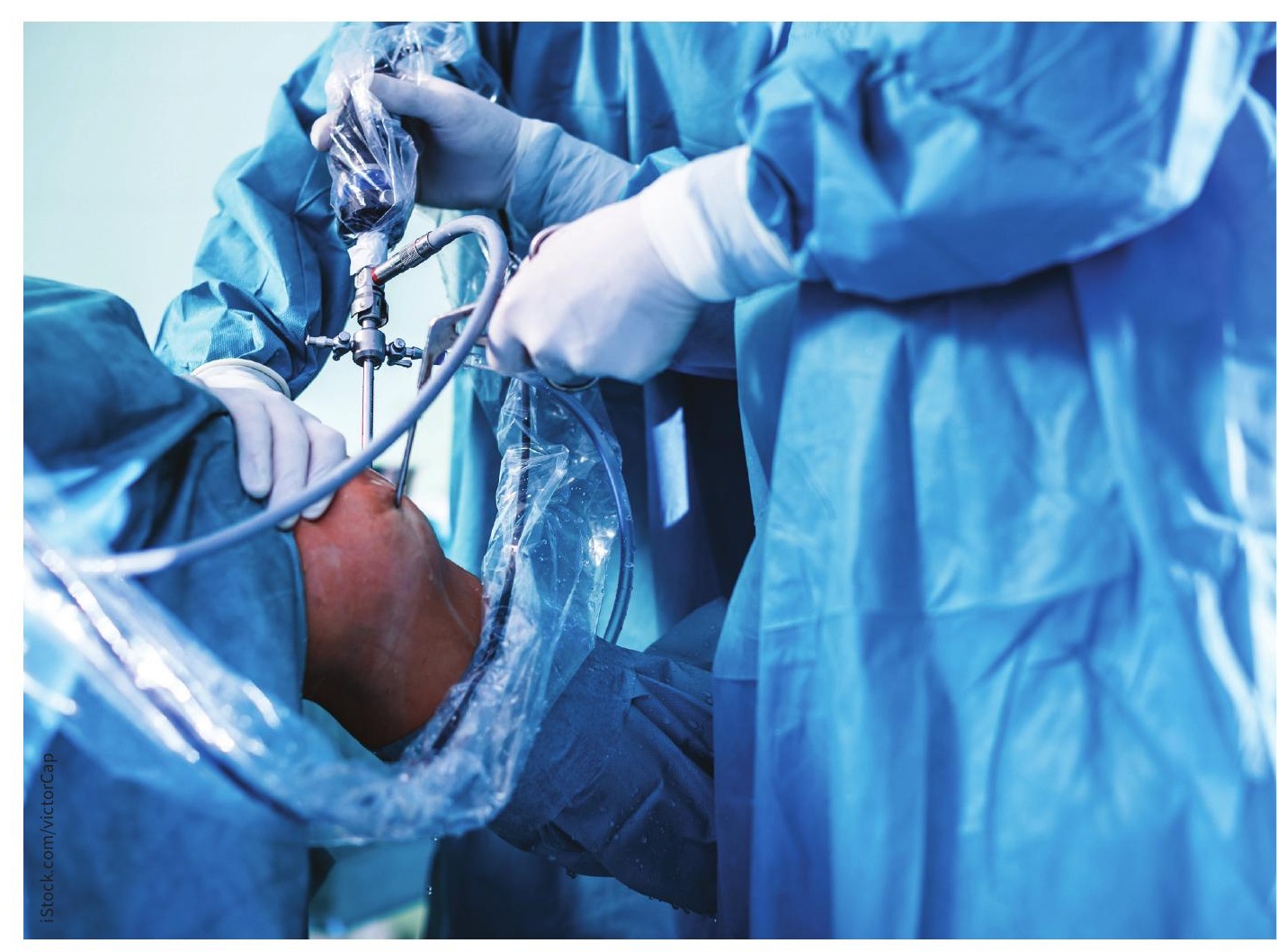

Demand for orthopedic services is increasing but newly certified surgeons are struggling to find jobs. gery, radiation oncology, nuclear medicine, urology and orthopedics. "The common thread is that they are all surgical or resource intensive," said Arun Shrichand, manager of health policy and advocacy at the Royal College, who worked on the survey. the Western world, he said. "By any metric, we are not over-training," he said. "It's not that people don't need more surgeons, but the government won't fund them."

Instead, said Antoniou, the problem is being addressed in "the worst possible 
way" - by reducing the number of residency positions in orthopedic surgery. That reduced the number of qualified surgeons looking for work over the past few years but will likely spell trouble in the future. Around 150 orthopedic surgeons are expected to retire over the next five years, he said, but Canada's aging population means demand for orthopedic services will only grow. "It will cause an even more acute problem later," said Antoniou. "We won't have enough capacity when retirements start to hit."

Ideas such as better workforce planning, increased funding and more cre- ative use of resources, such as running operating rooms on weekends, have been proposed to improve the employment situation for specialists. There are other simple steps that could also help. A more transparent approach to job advertisements and help with networking for newly qualified specialists would make it easier for them to find work. "A lot of survey respondents didn't know where the jobs were," said Shrichand. "It was often about word of mouth and having the right connections."

Those unable to find steady work right away tend to keep busy in other ways: fellowships, locum positions, extra call shifts, further training in a subspecialty. "After three to four years, a good number are able to find some makeshift solution, but it's not ideal," said Antoniou.

Many eventually end up leaving Canada for the United States or other countries where they will be able to practise in their chosen fields, taking their skills and the government's investment with them. "We advise them to be flexible about where they consider practising, either in Canada or internationally," said Fréchette. "Canadian credentials are highly regarded around the world."

Brian Owens, St. Stephen, NB 